\title{
REVIEWS
}

\section{Tumor control versus adverse events with targeted anticancer therapies}

\author{
Dorothy M. K. Keefe and Emma H. Bateman
}

\begin{abstract}
The advent of targeted anticancer therapies over the past few decades has reinvigorated the field of cancer therapeutics, with the promise of increased cancer cure rates accompanied by decreased toxicity. But, has that promise been fulfilled? The short answer is definitely 'no', both because of disappointing tumor responses and unexpectedly high toxicity, as well as the extremely high financial cost of these agents. However, failing to completely fulfill initial promise does not mean that targeted therapies should be abandoned. Increased progression-free survival might ultimately lead to increased overall survival, and targeted therapies have changed the course of cancers such as breast, lung and renal. Therefore, we would argue that despite some disappointments, targeted therapies have a vital role in future cancer treatment. This Review will discuss the positives and negatives of targeted agents, and propose a way to optimize their use and development to ensure proper personalized cancer medicine that tailors not only the anticancer treatment, but also the antitoxicity strategies, to achieve the best outcome for the patient in terms of both quality and quantity of life.
\end{abstract}

Keefe, D. M. K. \& Bateman, E. H. Nat. Rev. Clin. Oncol. 9, 98-109 (2012); published online 20 December 2011; doi:10.1038/nrclinonc.2011.192

\section{Introduction}

Anticancer therapy has always been hampered by the damage it inflicts on normal tissue. Conventional chemotherapy does not distinguish between normal and cancer cells, relying for success on its ability to kill cells, and on the ability of normal tissue to recover from damage more quickly and more successfully than tumor tissue. As progress is made in reducing toxicity by protecting normal tissue, or further enhancing its recovery, so the balance between tumor control and adverse effects is increasingly tipped in favor of anticancer effects. This can sometimes lead to the use of higher doses of chemotherapy in the hope of increasing response rates, a strategy that does not work particularly well. The search for targeted agents that can kill cancer cells but not normal tissue has been one of the 'holy grails' of cancer research.

With the introduction of the targeted therapy imatinib for the treatment of chronic myeloid leukemia $(\mathrm{CML}),{ }^{1,2}$ it was thought that this goal was in sight. However, CML is one of very few malignancies for which a single molecular mutation is both necessary and sufficient to cause the disease. Most other tumors have multiple mutations, the targeting of any single one of which is not sufficient for cure. Over the past two decades, targeted anticancer therapies have been tried in many malignancies with varying success. In some, a targeted therapy might work for a short time only, in others, the unexpected toxic effects have become an enormous problem, and in yet others, the

\section{Competing interests}

D. M. K. Keefe declares associations with the following companies: GlaxoSmithKline, Helsinn, Merck. See the article online for full details of the relationships. E. H. Bateman declares no competing interests. targeted therapy adds to the choice of agents that need to be used in combination or in sequence over the treatment course of the patient. In all cases, the balance between duration of life, quality of life, and cost of care needs to be maintained.

Nihilists dismiss the importance of cancer treatment, claiming that it is a waste of time and resources. ${ }^{3}$ Cancer, however, is a leading worldwide killer that cannot be ignored. The gradual increase in knowledge over the past six decades has resulted in incremental improvements in outcomes from cancer, with 5-year survival increasing from $35 \%$ in $1950-1954$ to $69.1 \%$ in $1999-2006 .{ }^{4}$ There has been an accompanying decrease in mortality of $8.8 \%,{ }^{4}$ and targeted therapies are contributing to this improvement. In addition, a great deal is now also known about how to prevent cancer. Healthy eating, exercise, sun-protection, stopping smoking, and minimizing alcohol intake will prevent approximately one third of cancers, ${ }^{5,6}$ so these strategies form a vital part of the overall cancer control picture. Furthermore, screening and vaccine development will also reduce cancer incidence.

\section{Incremental benefits of treatment}

The incremental benefits of new cancer treatments continue to accrue. For example, the combination regimen of bleomycin, etoposide and cisplatin has reduced the mortality of testicular cancer from $0.74 \%$ in 1975 to $0.22 \%$ in 2007; while improved therapies for breast and metastatic colorectal cancer (mCRC) have reduced their mortality rates from $31.25 \%$ to $22.84 \%$ and from $28.09 \%$ to $16.72 \%$, respectively, over the same period. ${ }^{4}$ Introduction of targeted agents adds another incremental improvement. For example, median overall survival for mCRC increased 
from 12 months with 5 -fluorouracil-folinic acid, ${ }^{7}$ to 18-24 months with oxaliplatin-based or irinotecan-based regimens, ${ }^{8}$ and the addition of the monoclonal antibody bevacizumab to chemotherapy combinations has pushed median overall survival above 30 months. ${ }^{9}$ The way we measure success has to be adjusted because targeted anticancer therapy often halts progression rather than shrinking the size of the tumor. This is a positive in itself as it can be translated into improved overall survival, but comes with the need for longer-term therapy.

Paradigm shifts in cancer treatments (both type and duration), however, are reflected in a shift in adverse events associated with targeted treatments. The very common acute chemotherapy toxicities of febrile neutropenia, nausea and vomiting and alopecia are much reduced with targeted anticancer therapies, but in our aging population, long-term targeted agent-induced adverse events represent a significant health and fiscal burden (Table 1). ${ }^{10}$ With a concomitant broadening of focus to include quality of life (QoL), management and prevention of adverse events is paramount, with a focus on the necessary compromise between adverse events and tumor control.

While some adverse reactions associated with the use of targeted agents can be unusual and unexpected, such as vision disturbances and hypothyroidism, ${ }^{11-13}$ these tend to be reversible and less severe than those associated with chemotherapy and/or radiotherapy. ${ }^{14,15}$ Cardiotoxicity is a significant toxic effect that can be induced by the monoclonal antibody trastuzumab, but it is reversible; ${ }^{16}$ however, doxorubicin-induced cardiotoxicity can be irreversible and life-threatening. ${ }^{17}$

\section{Targeted agents-the positives Imatinib and CML}

CML was the first cancer to have a documented molecular target. ${ }^{1,2}$ The protein product of the translocated gene $B C R-A B L$ has a deregulated tyrosine kinase activity that is successfully targeted by tyrosine kinase inhibitors (TKIs), such as imatinib (Table 1). Treatment of Philadelphiapositive CML with imatinib confers a significant survival advantage, ${ }^{2}$ with $80-90 \%$ of patients with chronic-phase CML undergoing a complete cytogenetic response. ${ }^{18}$ The trial that assessed imatinib in these patients (IRIS) demonstrated a progression-free survival (PFS) rate of $97 \%$ versus $80 \%$ (imatinib versus interferon- $\alpha$ ), and $95 \%$ overall survival after 18 months. ${ }^{19}$ The 7-year follow up of this study showed PFS and overall survival rates of $86 \%$ and $81 \%$, respectively. ${ }^{20}$ Other multicenter, randomized studies have shown similar PFS rates of approximately $80-90 \%$ for patients treated with imatinib. ${ }^{21}$ Imatinib, plus intensive chemotherapy, is the standard treatment for patients with $\mathrm{CML}$, and development of superior second-generation drugs, such as dasatinib and nilotinib, is ongoing. ${ }^{22,23}$ Imatinib treatment of CML is also more cost effective than the previous, less successful, interferon- $\alpha$ treatment. ${ }^{24}$

No other targeted therapy developed since imatinib has enjoyed such high success, because no other cancers have a single causal mutation. The development of colon cancer, for example, requires an accumulation of genetic changes

\section{Key points}

- Incremental benefits of cancer treatments over the past few decades have substantially improved survival and mortality rates for many cancer types; however, treatment-related toxicity remains a large problem

- Targeted therapies have contributed considerably to anticancer benefits; however, co-expression of many targets on normal cells means that toxicity is still a problem

- Despite toxicities and costs, targeted therapies have such a positive impact on progression-free survival and overall cancer survival, as well as quality of life, that their continued use is justified

- To further support use of targeted therapies, more research needs to be done on toxicity profiling, toxicity mechanisms and long-term follow-up analyses

- More research into targeted agents and their toxicities will further contribute to the repertoire of anticancer treatments, building on past success

- Successful cancer treatment in the future will be multidisciplinary, allowing for maximization of tumor control with concomitant minimization of adverse effects and cost of treatment

to move from normal, through benign polyp, to malignant polyp, to invasive cancer. ${ }^{25}$

\section{Trastuzumab and breast cancer}

Approximately $15-25 \%$ of breast cancers overexpress the HER2 receptor, which is associated with a more-aggressive form of the disease and a poor prognosis. ${ }^{26,27}$ Trastuzumab, a humanized monoclonal antibody that binds to the extracellular domain of HER2, is used to treat patients with metastatic HER2-positive breast cancer, either as a monotherapy or in combination with chemotherapy, and it is also used in the adjuvant setting to treat patients with early stage HER2-positive breast cancer who have undergone surgery, chemotherapy or radiotherapy. ${ }^{28}$ Landmark phase III trials of trastuzumab in combination with doxorubicin, cyclophosphamide and paclitaxel in patients with resected HER2-positive breast cancer showed a decrease in the risk of development of a second primary cancer by $52 \%$ and reduced relative risk of mortality by $33 \% .^{29,30}$

\section{Erlotinib and NSCLC}

Non-small-cell lung cancer (NSCLC) represents approximately $80-85 \%$ of all lung cancer diagnoses, and since most cases are well advanced at the time of diagnosis, surgery is often unsuitable. ${ }^{4,31}$ Treatment has improved considerably over the past two decades, from no effective treatment, to platinum-based chemotherapy (approximately 5\% improvement in 5-year survival), ${ }^{31}$ to targeted agents. Erlotinib is an oral TKI that competes with ATP for the ATP-binding site on the intracellular, tyrosine kinase domain of EGFR. This binding blocks downstream signaling, leading to cell-cycle arrest in the $G_{0}-G_{1}$ phase and, in some cases, causes apoptosis (Figure 1). NSCLC has a high expression of $E G F R^{32}$ and erlotinib is indicated for the treatment of NSCLC after failure of at least one prior chemotherapy regimen. Maintenance therapy with erlotinib is also recommended in metastatic NSCLC, in patients whose disease has not progressed after four cycles of first-line platinum-based chemotherapy. ${ }^{31}$ In one phase II trial, PFS was 2.1 months and overall survival was 6.7 months when erlotinib was used as third-line therapy in NSCLC; ${ }^{33}$ in a phase III trial, erlotinib (as maintenance 


\section{REVIEWS}

\begin{tabular}{|c|c|c|c|}
\hline Drug & Type of agent (target) & Indication(s) & Common toxic effects \\
\hline Imatinib & TKI (BCR-ABL kinase) & $\begin{array}{l}\text { GIST, CML, refractory or recurrent } \mathrm{Ph}+ \\
\mathrm{ALL} \text {, dermatofibrosarcoma protuberans }\end{array}$ & Fatigue, diarrhea, rash, nausea, cardiotoxicity, granulocytopenia $80,98,140$ \\
\hline Dasatinib & TKI (BCR-ABL kinase) & CML, ALL & Fatigue, diarrhea, rash, nausea, vomiting, edema, anemia, cardiotoxicity ${ }^{98,140}$ \\
\hline Nilotinib & TKI (BCR-ABL kinase) & $\mathrm{CML}$ & Fatigue, diarrhea, rash, nausea, vomiting, edema, anemia, cardiotoxicity ${ }^{99,140}$ \\
\hline Trastuzumab & mAb (HER2) & $\begin{array}{l}\text { Breast cancer, gastric cancer, } \\
\text { gastroesophageal adenocarcinoma }\end{array}$ & Fatigue, diarrhea, rash, cardiotoxicity, anemia, dyspnea, neutropenia $a^{16,26}$ \\
\hline Lapatinib & TKI (HER2, EGFR) & Advanced-stage metastatic breast cancer & Fatigue, diarrhea, rash, cardiotoxicity, hand-foot syndrome $e^{85,103}$ \\
\hline Gefitinib & TKI (EGFR) & Advanced-stage NSCLC & Diarrhea, rash, nausea, vomiting, mucositis, dyspnea ${ }^{32,80,83}$ \\
\hline Erlotinib & TKI (EGFR) & mNSCLC, pancreatic cancer & Fatigue, diarrhea, rash, anorexia ${ }^{80,141}$ \\
\hline Cetuximab & mAb (EGFR) & SCCHN, CRC & Fatigue, rash, anorexia, infusion reaction ${ }^{124,142,143}$ \\
\hline Panitumumab & $\mathrm{mAb}$ (EGFR) & $\mathrm{mCRC}$ & Fatigue, diarrhea, rash, nausea, anorexia, neutropenia ${ }^{144}$ \\
\hline Vandetanib & $\begin{array}{l}\text { TKI (EGFR, VEGFR, } \\
\text { Ret) }\end{array}$ & Medullary thyroid cancer & $\begin{array}{l}\text { Diarrhea, rash, hypertension, proteinuria, asymptomatic } \\
\text { QT prolongation }{ }^{143,145}\end{array}$ \\
\hline Bevacizumab & mAb (VEGF) & $\begin{array}{l}\text { Glioblastoma, NSCLC, metastatic breast } \\
\text { cancer, mCRC, mRCC }\end{array}$ & $\begin{array}{l}\text { Fatigue, diarrhea, anorexia, hypertension, abdominal pain, influenza-like } \\
\text { illness, pyrexia, gastrointestinal perforation, proteinuria, hemorrhage, } \\
\text { congestive heart failure, arterial thromboembolism, wound healing } \\
\text { problems }^{64,92}\end{array}$ \\
\hline Sorafenib & $\begin{array}{l}\text { TKI (VEGFR, PDGFR, } \\
\text { C-Raf, Flt3) }\end{array}$ & Advanced-stage RCC, HCC & $\begin{array}{l}\text { Fatigue, diarrhea, rash, nausea, vomiting, anorexia, hypothyroidism, } \\
\text { cardiotoxicity, hand-foot syndrome, dyspnea }\end{array}$ \\
\hline Sunitinib & $\begin{array}{l}\text { TKI (VEGFR, PDGFR, } \\
\text { c-Kit, Flt3, Ret) }\end{array}$ & $\begin{array}{l}\text { mRCC, GIST, pancreatic neuroendocrine } \\
\text { tumors }\end{array}$ & $\begin{array}{l}\text { Fatigue, diarrhea, nausea, vomiting, anorexia, dyspepsia, stomatitis, } \\
\text { hypothyroidism, hypertension, cardiotoxicity, hand-foot syndrome, skin } \\
\text { discoloration, dysgeusia } \\
64,98,100,143\end{array}$ \\
\hline Rituximab & $\mathrm{mAb}(\mathrm{CD} 20)$ & NHL, CLL & Fatigue, thrombocytopenia, neutropenia, pneumonitis, edema, dyspnea ${ }^{146}$ \\
\hline Alemtuzumab & $\mathrm{mAb}(\mathrm{CD} 52)$ & B-cell CLL & $\begin{array}{l}\text { Neutropenia, anemia, thrombocytopenia, infusion-related } \\
\text { reactions, infection }{ }^{147}\end{array}$ \\
\hline Ofatumumab & $\mathrm{mAb}(\mathrm{CD} 20)$ & CLL & $\begin{array}{l}\text { Neutropenia, anemia, thrombocytopenia, infusion-related } \\
\text { reactions, infection }{ }^{148}\end{array}$ \\
\hline Ipilimumab & mAb (CTLA-4) & Metastatic melanoma & Diarrhea, rash, dermatitis enterocolitis, hypophysitis, hepatitis ${ }^{149,150}$ \\
\hline
\end{tabular}

therapy) was associated with an improved PFS in patients who had stable disease or complete to partial response (hazard ratio $0.68 ; P<0.001$ ) and improved overall survival in patients with stable disease (hazard ratio 0.72 ; $P=0.0019)$ compared with placebo. ${ }^{34,35}$

\section{Gefitinib and NSCLC}

Gefitinib is most effective in patients with NSCLC who have mutations in EGFR, particularly in female non-smokers of East Asian background, with adenocarcinoma. ${ }^{32}$ The frequency of $E G F R$ mutation ranges from $40-80 \%$, with different mutations conferring different responses to different inhibitors; these mutations correlate strongly with demographic factors. ${ }^{32}$ In one study, $94.1 \%$ of patients with an EGFR mutation showed a radiographic response to treatment with gefitinib, compared with only $12.6 \%$ in those with wild-type EGFR. ${ }^{36}$

\section{Cetuximab and SCCHN}

Head and neck cancer represents $3 \%$ of cancers in the USA, and continues to have a high mortality rate (5.7 per 100,100 in 1987 versus 4.5 per 100,000 in 2008). ${ }^{4,37,38}$ Cetuximab is a chimeric mouse-human monoclonal antibody that binds with high affinity to EGFR, preventing ligand binding. 
Blocking agonist binding and downstream signaling results in cell-cycle arrest in the $\mathrm{G}_{1}$ phase (Figure 1). ${ }^{39}$ Now an established therapy for squamous-cell carcinomas of the head and neck (SCCHN), cetuximab showed promising results in combination with cisplatin in early phase I and phase II trials, with response rates ranging from $22 \%{ }^{40}$ to $67 \%{ }^{41}$ in refractory and advanced-stage SCCHN, respectively. Cetuximab was approved by the FDA in March 2006, either as a single agent in patients with SCCHN who had undergone prior platinum-based therapy, or in combination with radiotherapy. ${ }^{38}$ Phase III clinical trials also showed increases in overall survival, PFS and response rates in metastatic or recurrent SCCHN treated with platinum-based chemotherapy and cetuximab. ${ }^{42}$

\section{Bevacizumab and $\mathrm{mCRC}$}

For 50 years, standard chemotherapy for mCRC was fluoropyrimidine-based, with a poor overall survival of less than 12 months. ${ }^{43}$ In the mid-1990s, standard of care was modified to 5-fluorouracil-based regimens, increasing overall survival to approximately 12 months. ${ }^{7}$ Combination therapy with oxaliplatin and irinotecan increased overall survival to approximately 18 months, ${ }^{8}$ and sequential, crossover treatments with irinotecan, 5 -fluorouracil and leucovorin (IFL), and folinic acid, 5 -fluorouracil and oxaliplatin further increased overall survival to approximately 22 months. ${ }^{8}$ The introduction of targeted therapy, however, has further increased overall survival to more than 30 months $^{9}$ for this previously 'untreatable' disease. Bevacizumab, a human monoclonal antibody directed against VEGF, inhibits binding of all VEGF-A isoforms, blocking downstream signaling, resulting in cell-cycle arrest and apoptosis (Figure 1). This, in turn, inhibits angiogenesis, an essential process in solid tumor growth. Although bevacizumab as a single agent has minimal effects on response rate, combination with chemotherapy has shown a positive, additive effect. In a pivotal study by Hurwitz et al., ${ }^{44}$ bevacizumab combined with IFL was associated with increased response rate, PFS and overall survival, in previously untreated mCRC. The IFL combination has since been shown to be inferior to other chemotherapy regimens, but studies such as these paved the way for combination therapies for mCRC containing bevacizumab.

\section{Crizotinib and NSCLC}

Crizotinib is a dual TKI, targeting the kinases c-Met and ALK. Chimeric oncoproteins developed from ALK fusion with other genes mediate ligand-independent activation of ALK, giving rise to constitutive ALK activity. Inhibition of phosphorylation of the ALK tyrosine kinase domain downregulates the Ras/MEK/ERK and PI3K/Akt pathways, leading to apoptosis (Figure 1). ${ }^{13}$ The EML4-ALK fusion protein is associated with anaplastic large-cell lymphoma, as well as inflammatory myofibroblastic tumors, neuroblastoma and, particularly, adenocarcinoma of the lung in young, never-smokers. ${ }^{13,45}$ FDA approval for crizotinib and a companion diagnostic test has recently been fast tracked for use in patients with ALK-positive, latestage (locally advanced or metastatic) NSCLC. ${ }^{46}$ Several

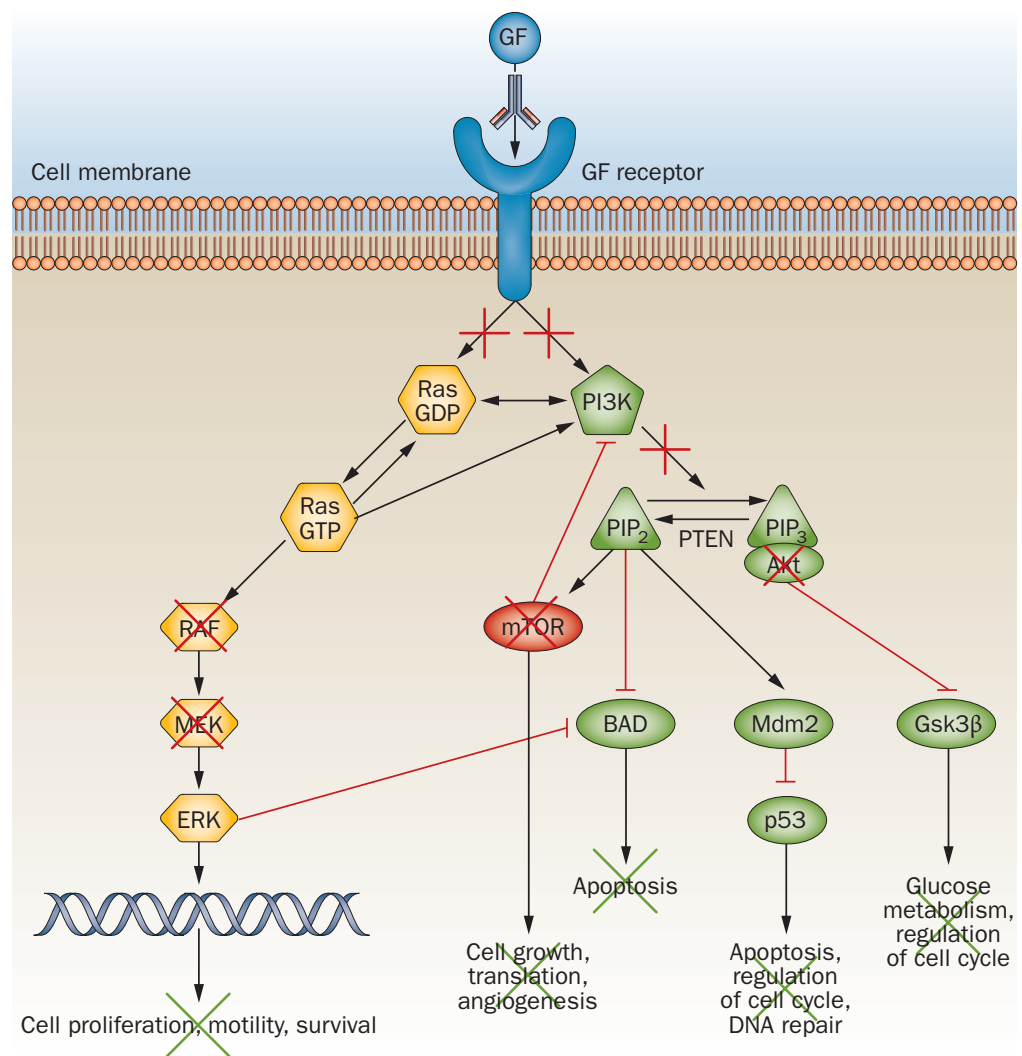

$$
\begin{aligned}
& \text { Inhibition of the protein by } \\
& \text { small-molecule targeted agent } \\
& \text { Inhibition of the protein by } \\
& \text { a monoclonal antibody }
\end{aligned}
$$

Figure 1 | Schematic diagram showing theoretical mechanisms of action of several types of targeting agents. There are several divergent and convergent pathways resulting from GF binding to the receptor, and consequently, several different points at which downstream effects may be abrogated. However, if one pathway is blocked by a specific targeting agent, this can be circumvented by using alternate pathway(s); this is the basis for resistance development. Abbreviations: GF, growth factor; Gsk3 $\beta$, glycogen synthase kinase-3 $\beta$; $\mathrm{PIP}_{2}$, phosphatidylinositol-1,4-bisphosphate; $\mathrm{PIP}_{3}$, phosphatidylinositol-1,4,5-trisphosphate.

clinical trials have shown dramatic improvements in crizotinib-treated patients with NSCLC, with reported PFS of 9.2 months. ${ }^{13,47}$ Phase III clinical trials using crizotinib with standard, single-agent chemotherapy in patients with metastatic NSCLC are ongoing.

\section{Ipilimumab and melanoma}

The incidence of melanoma has increased by approximately $2 \%$ per year since $1975,4,48$ and melanoma represents a major cancer burden; development of new therapies for melanoma is therefore a priority. Ipilimumab, a novel cytotoxic T-lymphocyte antigen-4 (CTLA-4) inhibitor, is approved by the FDA (Table 1) and is currently in clinical trials for melanoma. ${ }^{49}$ Ipilimumab binds to B7 receptors on T-lymphocytes, antagonizing the inhibitive action of CTLA-4, resulting in unrestrained T-lymphocyte proliferation and subsequent interleukin-2 production. This potentiates the immune response against immunogenic malignancies, such as melanoma. A clinical trial in 
676 patients with previously treated metastatic melanoma resulted in increased overall survival (10.0 months versus 6.4 months) when ipilimumab was administered with or without glycoprotein $100 .^{50}$

Activating mutations of B-Raf are estimated to be involved in approximately $60 \%$ of melanomas. ${ }^{51}$ Inhibitors of heat shock protein 90 (Hsp90) prevent phosphorylation of MEK and ERK pathways by degrading B-Raf protein products, which results in decreased cell signaling, proliferation and migration (Figure 1). Two Hsp90 inhibitors, PF-4470296 and PF-3823863 (Pfizer, New York, USA), exhibited antitumor activity in melanoma cell lines, ${ }^{52}$ and a phase III study of vemurafenib (a B-Raf inhibitor) versus dacarbazine in 675 patients carrying the V600E B-Raf substitution resulted in improved PFS of 5.3 months (vemurafenib) versus 1.6 months (dacarbazine) and an overall survival at 6 months of $84 \%$ (vemurafenib) versus $64 \%$ (dacarbazine). ${ }^{50,53-55}$

\section{PARP inhibitors and BRCA mutations}

PARP is involved in the repair of single-strand DNA breaks, and PARP inhibition leads to accumulation of these breaks into double-stranded breaks. This accumulation can be corrected by the homologous recombination repair pathway, components of which include the $B R C A 1$ and BRCA2 gene products. ${ }^{56}$ It has been shown that patients with loss of BRCA function are highly sensitive to PARP inhibition; and this has led to development of PARP inhibitors for the treatment of cancers with $B R C A 1$ and BRCA2 mutations. PARP inhibitors include olaparib, an orally-active PARP inhibitor that has shown efficacy in phase II trials in women with advanced-stage breast cancer. ${ }^{57}$ Objective response rate (ORR) was the primary outcome of this trial, with an ORR for the highdose cohort (400 mg olaparib twice daily) of $41 \%$, and an ORR for the low-dose cohort (100 mg olaparib twice daily) of $22 \% .{ }^{57}$ Median PFS was 5.7 months and 3.8 months for high-dose and low-dose cohorts, respectively. ${ }^{57}$ In a similar phase II study, patients with ovarian cancer were treated with the same high or low dose of olaparib; ORR for the high-dose cohort was 33\% (versus 13\% for the low-dose cohort), and median PFS for the high-dose cohort was 5.8 months (versus 1.9 months for the lowdose cohort).$^{58} \mathrm{~A}$ phase IB study of another PARP inhibitor, iniparib, in BRCA2-associated pancreatic cancer (and other solid cancers) with the addition of gemcitabine is ongoing, with promising results detailed in a case study by Fogelman et al..$^{59}$

\section{PI3K and mTOR inhibitors}

Mutations in the catalytic 110 a subunit of PI3K have been found in approximately $25 \%$ of patients with hormone receptor-positive, HER2-positive breast cancer, where upregulated activity of the PI3K pathway is observed. ${ }^{60}$ $\mathrm{PI} 3 \mathrm{~K}$ is activated when the cognate tyrosine kinase receptors (for example, IGF-1R and HER2) are activated, leading to the phosphorylation of $\mathrm{PIP}_{2}$ to $\mathrm{PIP}_{3}$ (Figure 1). Phase II studies of XL147 (Exelixis, San Francisco, USA and Sanofi-Aventis, Paris, France), an oral PI3K family inhibitor, are ongoing in patients with NSCLC and lymphoma, and a dual PI3K and mTOR inhibitor, NVP$\mathrm{BEZ235}$, is showing promising results in several cancer cell lines (Waldenström macroglobulinemia, ${ }^{61} \mathrm{RCC}^{62}$ and $\mathrm{HCC}^{63}$ ). Everolimus and temsirolimus are both mTOR inhibitors approved by the FDA for the treatment of patients with advanced-stage renal-cell carcinoma (Table 1), ${ }^{64,65}$ and have also shown promising activity against B-cell lymphomas. ${ }^{66}$

\section{IGF inhibitors}

IGF-1R has key roles in the growth and development of normal tissue via the activation of the PI3K pathway, but has also been shown to be upregulated in certain cancers. ${ }^{67,68}$ A humanized monoclonal antibody, figitumumab, ${ }^{69}$ has been shown in phase I trials to abrogate upregulated IGF-1R (Figure 1), in refractory melanoma, Ewing's sarcoma and adrenocortical tumors, in combination with docetaxel. ${ }^{6}$ Phase III trials of figitumumab efficacy in NSCLC were abandoned owing to a large number of deaths in the experimental arm. ${ }^{70}$ Another IGF-1R inhibitor, ganitumab, has demonstrated a PFS of 2.3 months in patients with Ewing's sarcoma, ${ }^{68,71}$ and is currently in a phase III trial for the treatment of metastatic adenocarcinoma of the pancreas. ${ }^{72}$

\section{Targeted agents-the negatives}

The double-edged sword of 'targeted' therapy originates in its specificity. ${ }^{73}$ Although targeted anticancer agents target particular signaling systems that are upregulated in tumor growth, many of these signaling pathways also exist in healthy cells. However, this crossreactivity is not absolute when it comes to tumor response-not all targeted agents are effective against the same target in different tumors. ${ }^{74}$ These different responses to targeted agents in different tumors occur for a number of reasons: heterogeneity in mutations of the molecular target (for example, EGFR mutations in $\mathrm{NSCLC}^{74}$ ), reactivation of oncogenetic pathways via secondary mutations (for example, in imatinib-refractory GIST ${ }^{75}$ ), and multiple pathway redundancy and branched interactions between cell signaling networks. ${ }^{76}$ These reasons for the heterogeneity of response might also explain why targeted anticancer therapy-induced toxic effects differ between patients. ${ }^{74-78}$

In patients treated with targeted therapies, although there may be fewer of the 'standard' toxicities usually associated with chemotherapy, such as emesis or neutropenia, there is a rise of a new group of frequently occurring adverse events, such as skin, vascular, cardiac and gastrointestinal toxic effects, probably caused by receptor crossreactivity or the presence of receptors on or in noncancerous cells. ${ }^{15}$ Other toxic effects associated with targeted therapies include aphthous mouth ulcers (which differ from chemotherapy-induced oral mucositis; the differences in pathobiology may also be reflected in other targeted anticancer therapy-induced toxicities), ${ }^{79}$ vomiting, nausea, fatigue, proteinuria, venous thromboembolism and hypothyroidism. ${ }^{80-82}$ Proactive management of these adverse events is often effective and allows for uninterrupted, full-dose or minimally altered-dose therapy with targeted agents (Box 1)..$^{83,84}$ 


\section{Dermal toxicity}

Cutaneous side effects are most often observed in association with EGFR inhibitors, such as lapatinib, panitumumab, gefitinib, erlotinib and cetuximab, ${ }^{85}$ and occur in over $50 \%$ of patients. ${ }^{86}$ They include papulopustular rash, folliculitis, alopecia, enhanced hair growth on the face, xerosis, pruritis, paronychia and thinning of the stratum corneum and epidermis. ${ }^{86}$ Inhibition of EGFR signaling in epidermal and follicular keratinocytes results in decreased cell proliferation, differentiation and attachment. Cutaneous adverse events are dose dependent and generally resolve spontaneously or after cessation of treatment ${ }^{85}$ however, they have a significant impact on QoL and might require intervention. Treatment remains supportive (Box 1), and focuses on the use of moisturizers and suncreams, and avoidance of alcohol-based products. In severe cases, however, topical hydrocortisone should be applied to affected areas and/or oral clindamycin may be administered. ${ }^{87}$ Cutaneous reactions can be a positive predictor of tumor response, thought to reflect receptor saturation and blockade. ${ }^{88}$

\section{Vascular toxicity}

In normal vessels, VEGF promotes vascular tone by induction of nitric oxide synthesis; disruption of normal signaling leads to a decrease in nitric oxide and subsequent prostaglandin production, which results in an increase in vascular resistance and blood pressure. ${ }^{89}$ Hypertension occurs primarily in association with monoclonal inhibitors of VEGF and its receptor (VEGFR), but also occurs with other classes of targeted therapies (such as the TKIs sunitinib, pazopanib and vandetanib and mTOR inhibitor temsirolimus; Table 1). Hypertension is an established risk factor for coronary heart disease, stroke, heart failure, and end-stage renal disease. ${ }^{90}$ Overall incidence of hypertension with any VEGF inhibitor ranges from $15 \%$ to $60 \%$, with bevacizumab associated with an incidence of up to $32 \%$, with a relative risk of 7.5 (versus 6.1 for sorafenib, and 3.9 for sunitinib)..$^{43,90,91}$ Patients with an underlying history of hypertension are especially at risk for developing VEGFR inhibitorinduced hypertension. ${ }^{89}$ Management of targeted therapyinduced hypertension can include treatment with agents such as angiotensin-converting enzyme inhibitors to lower blood pressure (Box 1).

Other serious adverse events associated with VEGF and VEGFR inhibitors are arterial and venous thromboembolic events, which are particularly associated with bevacizumab use $\mathrm{e}^{43,92,93}$ and can lead to stroke or myocardial infarction. Gastrointestinal perforation is a significant adverse event for at least $1.5 \%$ of patients treated with bevacizumab, ${ }^{73,93}$ but case studies have also described gastrointestinal perforation in association with the use of sorafenib, gefitinib and sunitinib. ${ }^{94,95}$ Other vascular functions, such as wound healing and hemostasis (Box 1), are also adversely affected by the use of VEGFR inhibitors, which is of particular concern when surgery is also involved in cancer treatment. In the case of bevacizumab, discontinuation is recommended for at least 60 days before surgery, and therapy should be resumed no earlier
Box 1 | Targeted anticancer therapy-related toxic effects and their management

Dermal toxicity $83,87,111$

Supportive only; patient education in pre-emptive management is vital.

Management includes:

- Moisturizers and suncreams; physical sun protection favored over chemical

- Avoidance of alcohol-based products

- Avoidance of extreme temperatures, wind, rain, frost

- Short, warm showers

- Rubber gloves for household activities

- Comfortable shoes with cushioned soles (for hand-foot skin reaction)

- In severe cases, topical hydrocortisone or clindamycin, or treatment with an oral tetracycline

Vascular toxicity ${ }^{15,82,92,94,157}$

For mild to moderate hypertension (up to grade 3):

- Treatment with angiotensin-converting enzyme inhibitors, angiotensin-II receptor antagonists; care must be taken if calcium channel blockers or $\beta$-blockers are used, as they might exacerbate PR interval prolongation

- Daily blood pressure monitoring

- Dose interruption until blood pressure $<150 / 100 \mathrm{mmHg}$

- In the case of severe hypertension (blood pressure $>200 / 110 \mathrm{mmHg}$ ), permanent cessation of treatment

For gastrointestinal perforation:

- Discontinuation of bevacizumab at least 60 days before surgery, and initiated no earlier than 28 days after surgery; in patients with comorbid conditions ideal interval is 6-8 weeks

For hemorrhage-usually only mild skin bruising, so treatment is cosmetic.

For more-severe bleeding:

- Education regarding internal bleeding symptoms

- Interruption of treatment for acute decreases in hemoglobin (>2 g/dl); evaluate until hemoglobin levels stabilize

- More-severe bleeds might require transfusion or surgery

- Analgesics if pain is experienced, for example, with subungual splinter hemorrhages

Cardiotoxicity ${ }^{96,98}$

Management best when pre-emptive; optimization of cardiovascular hemodynamics before therapy is recommended:

- Baseline measurement of left ventricular ejection fraction and blood pressure

- Cardiac workup, including electrocardiogram and echocardiogram before treatment

- At any signs of heart failure, treatment should be interrupted, and resumed at a reduced dose when heart function stabilizes

Gastrointestinal toxicity ${ }^{83,111,158}$

Supportive only; patient education in pre-emptive management is vital.

Management includes:

- Adequate hydration and electrolyte balance

- Consumption of bland foods

- Orally administered tyrosine kinase inhibitors to be taken with the largest meal of the day to minimize nausea, or at bedtime

- Anti-nausea or anti-emetics in moderate to severe cases of nausea or vomiting; prochloroperazine or ondansetron

- Loperamide, atropine sulfate or diphoxylate hydrochloride for moderate to severe cases of diarrhea; in severe cases, tincture of opium, hospitalization and intravenous rehydration might be required

than 28 days after surgery, ${ }^{92}$ with an ideal interval of 6-8 weeks (Box 1). ${ }^{96}$ However, expert opinion suggesting a shorter break is beginning to emerge. ${ }^{97}$

\section{Cardiotoxicity}

Cardiotoxicity can be a short-term or long-term complication of targeted therapy, and can range from asymptomatic, subclinical abnormalities (such as QT prolongation and left ventricular ejection fraction 
Table 2 | Well-established targeted therapies and associated cost

\begin{tabular}{ll}
\hline Drug & Approximate cost per QALY \\
\hline Trastuzumab & $\$ 50,000-\$ 70,000$ in metastatic breast cancer ${ }^{118,151}$ \\
\hline Bevacizumab & $\$ 100,000$ in $\mathrm{mCRC}^{-152} \$ 50,000$ in NSCLC \\
\hline Erlotinib & $\$ 37,000$ in NSCLC \\
\hline Sunitinib & $\$ 50,000$ in $\mathrm{mRCC}^{121}$ \\
\hline Rituximab & $\$ 50,000$ in $\mathrm{NHL}^{155}$ \\
\hline Imatinib & $\$ 45,000$ in $\mathrm{CML}^{156}$ \\
\hline $\begin{array}{l}\text { Abbreviation: CML, chronic myeloid leukemia; } \\
\text { colorectal cancer; quality-adjusted life year; mCRC, metastatic } \\
\text { non-small-cell lung cancer. }\end{array}$ &
\end{tabular}

[LVEF] decline) to life-threatening conditions (such as congestive heart failure or acute coronary symptoms).$^{27}$ Expression of receptor targets on cardiac cells, such as HER2, EGFR and VEGFR, is likely responsible for the cardiotoxicity of therapies targeted against these receptors. ${ }^{26}$ Imatinib, dasatinib, nilotinib, sunitinib, sorafenib, lapatinib and bevacizumab have all been associated with cardiotoxicity, the mechanisms of which are as yet unclear. ${ }^{98,99}$ Trastuzumab is particularly associated with cardiotoxicity, ${ }^{98}$ which is not dose dependent, occurs without changes to tissue structure, and tends to be reversible. ${ }^{14,99}$

In the case of TKI-induced cardiotoxicity, it might be that the competition for the ATP-binding site posed by TKIs is particularly a problem in cardiomyocytes, which have an enormous energy requirement. ${ }^{100}$ It is recommended that patients undergoing treatments with potential cardiac side effects have prior clinical evaluation and assessment of cardiovascular risk factors and comorbidities, as well as baseline measurement of LVEF and weekly monitoring of blood pressure (Box 1). ${ }^{15,98,101}$ It has also been recommended that cardiovascular hemodynamics are optimized before therapy, to further reduce the risk of developing a severe cardiac adverse event. ${ }^{99}$

\section{Gastrointestinal toxicity}

As with traditional cytotoxic cancer treatments, diarrhea is the most common gastrointestinal manifestation of targeted therapy use. ${ }^{102}$ The mechanisms of toxicity are assumed to be secretory (with no supporting evidence); ${ }^{103,104}$ however, they might be different to that of chemotherapy-induced diarrhea. ${ }^{105,106}$ Targeted therapyinduced diarrhea is usually mild to moderate in severity; however, when targeted therapies are used in combination with chemotherapy or other targeted agents, severe diarrhea can result, leading to dose modifications. ${ }^{107}$ Similarly to chemotherapy-induced diarrhea, treatment of targeted therapy-induced diarrhea is supportive, and can be treated successfully with loperamide. ${ }^{108}$ Diarrhea is associated in particular with therapies that target EGFR, especially oral TKIs such as erlotinib and gefitinib, ${ }^{32,83}$ and the mAbs cetuximab, panitumumab, bevacizumab and trastuzumab. ${ }^{83,92,107,109}$ TKIs targeting HER2 and VEGFR, such as lapatinib, sunitinib and sorafenib, ${ }^{103,110}$ have also been implicated in the induction of diarrhea. Promiscuity of many of these targeted agents for other receptors is thought to be partly responsible for common toxicities; however, basic research is continuing to shed light on the exact pathogenesis of targeted therapy-induced diarrhea. ${ }^{73,109,111}$

\section{Cost of targeted therapies}

Since targeted therapies are a relatively new treatment, few data exist on long-term follow up, which presents a problem when considering the balance between cost, adverse events and tumor control. Many people will agree that large benefits to a few should be prioritized if those benefits are lifesaving; however, those concerned with fiscal burdens argue that the greatest good for the greatest number is a better aim. ${ }^{10}$

The direct costs of targeted anticancer treatment are considerable. It is estimated, for example, that a year of treatment with trastuzumab costs approximately $\$ 70,000-100,000 .^{112}$ Although cancer currently drives 5\% of health-care costs, this will increase significantly owing to increased detection and diagnosis, the aging population and escalating costs of newer therapies. ${ }^{10}$ Indirect costs associated with targeted anticancer therapies are more complex and multifactorial. They may be related to mutation screening and diagnosis, psychosocial and QoL changes, and toxicity management.

Mutation screening allows for tailored treatment to patients who will best benefit from a particular targeted therapy, but these technologies can be expensive and operator biased. ${ }^{113,114}$ An important issue to consider with such tests is the frequency of the mutation in question-how frequent does it have to be to justify the cost? Screening for rare mutations will help those few positive patients who consequently receive tailored treatment; however, it is likely a waste of time and resources if most patients do not carry the mutation. Screening for morecommon mutations, such as BCR-ABL (CML), EGFR (NSCLC), and HER2 (breast cancer) allows for moretailored treatments, minimizing costs in the long run. ${ }^{113}$ However, this is dependent upon the standardized use of these tests, which needs to be absolute to achieve maximum benefit and minimum cost.

Toxicity management must be addressed in a longterm manner owing to the tumor control successes of targeted therapies, which has turned many cancers into chronic illnesses. Development of a lifelong condition initiated by cancer treatment, such as cardiotoxicity or hypertension, might need lifelong monitoring and medication, which increases cost and QoL burdens. These costs can be offset, however, with better management of chronic toxicities. Most follow-up tasks do not need to be performed by a specialist, but can be performed by nursing staff, or the patients themselves. Patientreported monitoring using real-time charting of status is an invaluable tool for the chronic monitoring of targeted therapy-related toxicity, ${ }^{115,116}$ and leads to reduced cost burden in the long run. Equipping workplaces with the tools necessary to adequately care for cancer survivors with chronic side effects is also essential. ${ }^{117,118}$

QoL has become one of the key considerations in decisions related to cancer treatment, and significantly 
influences the indirect costs associated with cancer treatment. It is also important to take into account the QoL of family members, who might also experience loss of productivity, psychosocial problems and exhaustion of savings through caring for the cancer patient. ${ }^{118}$ Workplaces can also suffer from an employee's cancer survival; although the patient might be able to work because of successful targeted anticancer treatment, compromises must be made to reduce loss of productivity. Education and training of employers to accommodate cancer survivors is important in the workplace, but also increases the indirect costs of targeted anticancer therapy. ${ }^{119}$

\section{Evolving cost-effectiveness models}

The direct cost for targeted therapy far outweighs that of traditional chemotherapy and/or radiotherapy; however, adjustment for QoL into calculation of life years gained (Table 2), usually tips the scales in favor of targeted therapy. It is no longer sufficient to base the success of an anticancer treatment on increased survival or prevention of mortality; QoL measures, particularly those reported by the patient themselves, are progressively becoming an essential part of the calculation of cost effectiveness. ${ }^{28}$ The round figure of $\$ 50,000$ per quality-adjusted life year has been the acceptable threshold (based on the cost of dialysis in end-stage renal disease in the late 1980s), but this is out-dated and ill-defined. ${ }^{120}$

Economic evaluations of cost of cancer care are often inconsistent, making it difficult for patients and physicians to make benefit-versus-cost decisions. Toxicityrelated costs are now a common adjustment. However, gains or losses in workplace productivity and the psychosocial impact of cancer survival are inconsistently included, making cost-effectiveness estimations unreliable. ${ }^{121,122}$ More research into cost-effectiveness models is required to incorporate the growing number of variables that influence cancer-care costs. ${ }^{14,121}$

\section{Optimizing use and development}

Improved strategies to anticipate, prevent and manage toxicities in a timely, supportive and tailored manner, will considerably reduce their burden without compromising antitumor effects. ${ }^{11,123}$ More-comprehensive reporting of side effects in clinical trials will prevent later 'unexpected' toxicities and keep people more realistic about the compromise between adverse events and tumor control. Measures to provide supportive care to deal with unanticipated adverse events and to increase QoL require money that might be better spent by investing in consultation with toxicologists in early drug development; it is more useful to know which patients will respond before the money is spent.

\section{Incorporating toxicity into drug development}

The journey of a new anticancer drug from bench to bedside is long, and is associated not only with tumor control, but also with toxicity. Extreme toxicity is dose limiting, for standard chemotherapy and/or radiotherapy and for targeted agents. Unfortunately, some level of

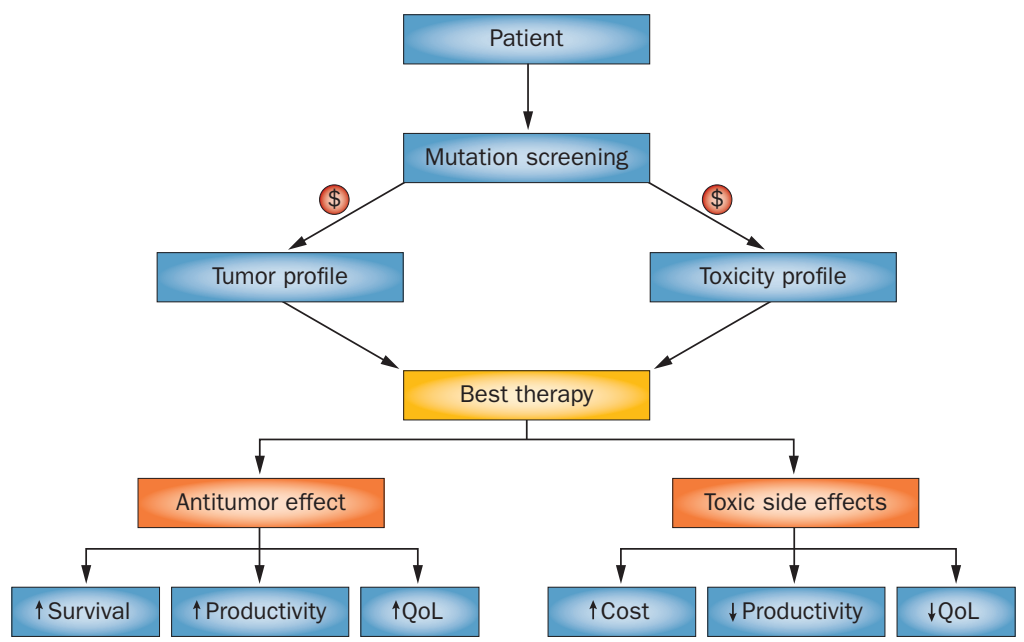

Figure 2 | Increased tumor control and decreased toxicity. How increased research into toxicity profiles will reduce downstream cost of care. Abbreviation: QoL, quality of life.

toxicity is almost inevitable, regardless of treatment. The focus of drug development should therefore be not only on the anticancer effects, but also on toxicity minimization. This would be aided by adequate toxicity measurement and reporting in clinical trials.

Targeted anticancer therapies should be used where they can make a real difference. We need to know when to start and stop using them. Development of an unexpected toxicity may result in a knee-jerk reaction to manage it; for example, cardiotoxicity resulting from therapy might call for an emergency cardiology consult. It may be that a particular adverse event is accepted as a necessary compromise in light of beneficial tumor control, as long as the toxicity is adequately predicted and managed. In many cases, these adverse events can be biomarkers of efficacy, ${ }^{88,124}$ such that the presence of such a toxic effect, if anticipated and managed properly, is actually a positive outcome of targeted therapy use. Examples include rash, which occurs in $85 \%$ of patients undergoing anti-EGFR therapy, ${ }^{125}$ hypertension, especially with the use of VEGF and VEGFR inhibitors, ${ }^{126,127}$ and hypothyroidism in the case of sunitinib treatment in $\mathrm{mRCC}{ }^{128}$

\section{Profiling of cancer patients}

It is important not only to classify those patients who will benefit from a particular treatment, but also those who might be harmed. The multi-mutational nature of cancer, coupled with the high variability in patient responses to any given agent, means that toxicity prediction is not always straightforward. The expression levels of a particular receptor target do not necessarily predict the response to inhibitors, ${ }^{129}$ and toxicity likewise depends on many confounders, including ethnicity, sex, age and smoking status. Clinical trials incorporating population studies will increase awareness of confounder bias, resulting in more-comprehensive toxicity data. An ideal model would combine tumor and toxicity profiling for each patient (Figure 2). 


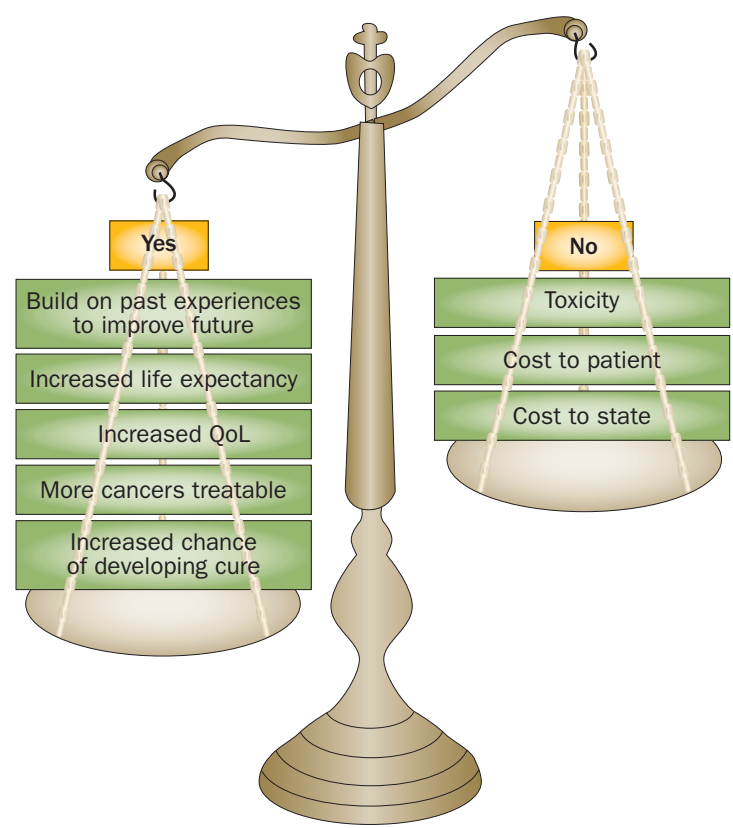

Figure 3 | Should targeted anticancer therapy be used in the clinic? Abbreviation: QoL, quality of life.

\section{Assessment of biomarkers}

It is important to have adequate technologies for the assessment of biomarkers of targeted therapy efficacy and toxicity. Measurements such as immunohistochemistry to determine protein-expression levels are often suboptimal; however, more-reliable, sensitive tests, are often very expensive. One example is miRome profiling; microRNAs (miRs) are small, noncoding RNA molecules that are evolutionarily conserved, and function as negative regulators of genes post-transcription. They have been shown to have a vital role in carcinogenesis, and oncogenic miR signatures associated with individual cancers can be profiled to give a simultaneous diagnosis and exact target for therapy. ${ }^{130,131}$ Confidence in the biological relevance of the biomarker is essential for the validation of assays, enabling optimization of targeted therapy use. ${ }^{132}$ Further research into the relevance of biomarkers and related detection technologies is vital for more-comprehensive profiling of not only patient cohorts, but also of the toxicities of individual therapies.

MTD: outdated end point for toxicity management Determination of an appropriate end point is another challenge in the development of targeted agents. Doseefficacy curves of standard agents often overlap with the dose-toxicity curves, so the maximum tolerated dose (MTD) as an end point is a necessary compromise between the two. Development of targeted agents aims to separate the dose efficacy and toxicity curves in order to maximize anticancer effects and minimize adverse effects. As such, MTD is becoming an outdated end point. ${ }^{133,134}$ It is known that some serious adverse events associated with targeted therapies can occur at relatively low doses of the agent, and in a dose-independent manner. ${ }^{133,134}$ It has, therefore, been put forward that the terms 'optimal biological dose' or 'minimum effective dose' be applied in lieu of the MTD. ${ }^{134}$

Problems do exist, however, in discarding MTD, as it is necessary to rely on biomarkers as evidence of biological activity. Measurement of these biomarkers is timeconsuming and expensive, whereas the MTD is an easily measured end point. Some targeted therapies might not have a discernible MTD, usually leaving cost as the limiting factor. ${ }^{134}$ However, it may be more acceptable to use a higher than strictly necessary dose of targeted therapy rather than risk poor tumor control and the development of resistance owing to under-dosing. ${ }^{135}$

\section{Improved strategies for targeted agent toxicity}

Treating the toxicities of targeted agents presents unique problems. Any treatment to prevent or reduce targeted therapy toxicity must not reduce antitumor effect. Since toxicities are often related to crossreactivity between host and cancer tissue, treatment of toxicities is likely to interfere with the tumor target as well as protect the host tissues. ${ }^{136}$

\section{Holistic approach to individualized treatment}

It is increasingly evident that successful treatment with targeted anticancer therapy is a balancing act. ${ }^{137}$ Cost is a major consideration, particularly when patients require multidisciplinary supportive care. Incorporation of realtime patient-reported outcomes ${ }^{138}$ in toxicity assessments are invaluable to accurately chart progression of any adverse events, and determine whether the cost of these adverse events outweighs any benefits from the treatment.

\section{Conclusions}

Should targeted anticancer therapy be used in the clinic? The answer is yes, (Figure 3). Overall, development of targeted therapies has had a significantly positive impact on cancer survival and mortality rates, and also QoL of cancer patients. The biggest problem posed by targeted agents is maintaining the balance between tumor control and toxicity, while being mindful of the cost. This can be addressed in the future by focusing on improved patient profiling to predict disease response and toxicity, long-term followup studies, and more research into the basic mechanisms of targeted therapy-related toxicity. The days of patients having to grin and bear adverse effects in the quest for tumor control are over; like Newton, we can stand on the shoulders of giants to fine-tune what is a rapidly expanding, successful modality of cancer treatment, using our past experiences to help open the door of the future.

Review criteria
The information for this Review was compiled by
searching PubMed and MEDLINE databases. Searches
using the following key words or phrases were performed:
"tumor control”, "adverse events/effects", "guidelines",
"toxicity", "biological targeting", "cost-effectiveness",
"anti-cancer and targeted therapy". More-specific
searches were performed for particular sections, and
literature was screened for relevance.


1. Frankel, A. E., Fleming, D. R., Powell, B. L. \& Gartenhaus, R. DAB389IL2 (ONTAK) fusion protein therapy of chronic lymphocytic leukaemia. Expert Opin. Biol. Ther. 3, 179-186 (2003).

2. Kantarjian, H. et al. Survival advantage with imatinib mesylate therapy in chronic-phase chronic myelogenous leukemia (CML-CP) after IFN-alpha failure and in late CML-CP, comparison with historical controls. Clin. Cancer Res. 10, 68-75 (2004).

3. Ryan, R. Cancer research-a super fraud? [online], http://www.pnc.com.au/ cafmr/ online/research/cancer.html (1997).

4. NCl. Cancer Trends Progress Report 1975-2006 [online], http://progressreport.cancer.gov (2010).

5. Danaei, G. et al. The preventable causes of death in the United States: comparative risk assessment of dietary, lifestyle, and metabolic risk factors. PLoS Med. 6, e1000058 (2009).

6. WHO. World Cancer Report 2002: Reducing Risk Promoting Healthy Life [online], http:// whalibdoc.who.int/hq/2002/WHO WHR_02.1.pdf (2003).

7. Saltz, L. B. et al. Irinotecan plus fluorouracil and leucovorin for metastatic colorectal cancer. Irinotecan Study Group. N. Engl. J. Med. 343 905-914 (2000)

8. Goldberg, R. M. et al. A randomized controlled trial of fluorouracil plus leucovorin, irinotecan, and oxaliplatin combinations in patients with previously untreated metastatic colorectal cancer. J. Clin. Oncol. 22, 23-30 (2004).

9. Grothey, A. et al. Bevacizumab beyond first progression is associated with prolonged overall survival in metastatic colorectal cancer: results from a large observational cohort study (BRiTE). J. Clin. Oncol. 26, 5326-5334 (2008).

10. Schnipper, L. E., Meropol, N. J. \& Brock, D. W. Value and cancer care: toward an equitable future. Clin. Cancer Res. 16, 6004-6008 (2010).

11. Di Lorenzo, G. et al. Toxicities of targeted therapy and their management in kidney cancer. Eur. Urol. 59, 526-540 (2011).

12. Gadgeel, S. M. \& Bepler, G. Crizotinib: an anaplastic lymphoma kinase inhibitor. Future Oncol. 7, 947-953 (2011).

13. Shaw, A. T. \& Solomon, B. Targeting anaplastic lymphoma kinase in lung cancer. Clin. Cancer Res. 17, 2081-2086 (2011).

14. Ewer, M. S. et al. Reversibility of trastuzumabrelated cardiotoxicity: new insights based on clinical course and response to medical treatment. J. Clin. Oncol. 23, 7820-7826 (2005).

15. Ravaud, A. How to optimise treatment compliance in metastatic renal cell carcinoma with targeted agents. Ann. Oncol. 20 (Suppl. 1), i7-i12 (2009).

16. Garnock-Jones, K. P., Keating, G. M. \& Scott, L. J. Trastuzumab: A review of its use as adjuvant treatment in human epidermal growth factor receptor 2 (HER2)-positive early breast cancer. Drugs 70, 215-239 (2010).

17. Lacko, A. et al. Cardiac toxicity in cancer therapy [Polish]. Pol. Merkur. Lekarski 13, 79-85 (2002).

18. Kantarjian, H. et al. Hematologic and cytogenetic responses to imatinib mesylate in chronic myelogenous leukemia. N. Engl. J. Med. 346 645-652 (2002).

19. O'Brien, S. G. et al. Imatinib compared with interferon and low-dose cytarabine for newly diagnosed chronic-phase chronic myeloid leukemia. N. Engl. J. Med. 348, 994-1004 (2003).

20. O'Brien, S. G. et al. International randomized study of interferon versus STI571 (IRIS) 7-year follow-up: sustained survival, low rate of transformation and increased rate of major molecular response (MMR) in patients (pts) with newly diagnosed chronic myeloid leukemia in chronic phase (CMLCP) treated with imatinib (IM) [abstract]. ASH Annual Meeting Abstracts 112, a186 (2008).

21. de Lavallade, H. et al. Imatinib for newly diagnosed patients with chronic myeloid leukemia: incidence of sustained responses in an intention-to-treat analysis. J. Clin. Oncol. 26, 3358-3363 (2008).

22. An, X. et al. BCR-ABL tyrosine kinase inhibitors in the treatment of Philadelphia chromosome positive chronic myeloid leukemia: a review. Leuk. Res. 34, 1255-1268 (2010).

23. Bumbea, H. et al. Chronic myeloid leukemia therapy in the era of tyrosine kinase inhibitorsthe first molecular targeted treatment. J. Med. Life 3, 162-166 (2010).

24. Chen, Z., Wang, C., Xu, X. \& Feng, W. Costeffectiveness study comparing imatinib with interferon-alpha for patients with newly diagnosed chronic-phase (CP) chronic myeloid leukemia $(\mathrm{CML})$ from the Chinese public healthcare system perspective (CPHSP). Value Health 12 (Suppl. 3), S85-S88 (2009).

25. Morton, R. F. \& Hammond, E. H. ASCO Provisional Clinical Opinion: KRAS, cetuximab, and panitumumab-clinical implications in colorectal cancer. J. Oncol. Pract. 5, 71-72 (2009).

26. Raschi, E. et al. Anticancer drugs and cardiotoxicity: Insights and perspectives in the era of targeted therapy. Pharmacol. Ther. $\mathbf{1 2 5}$, 196-218 (2010).

27. Curigliano, G., Mayer, E. L., Burstein, H. J., Winer, E. P. \& Goldhirsch, A. Cardiac toxicity from systemic cancer therapy: a comprehensive review. Prog. Cardiovasc. Dis. 53, 94-104 (2010).

28. Soria, J. C. et al. Added value of molecular targeted agents in oncology. Ann. Oncol. 22, 1703-1716 (2011)

29. Romond, E. H. et al. Trastuzumab plus adjuvant chemotherapy for operable HER2-positive breast cancer. N. Engl. J. Med. 353, 1673-1684 (2005)

30. Slamon, D. J. et al. Use of chemotherapy plus a monoclonal antibody against HER2 for metastatic breast cancer that overexpresses HER2. N. Engl. J. Med. 344, 783-792 (2001).

31. Gridelli, C. et al. Erlotinib in the treatment of nonsmall cell lung cancer: current status and future developments. Anticancer Res. 30, 1301-1310 (2010).

32. Gupta, A. \& Raina, V. Geftinib. J. Cancer Res. Ther. 6, 249-254 (2010).

33. Matsuura, S. et al. Phase II study of erlotinib as third-line monotherapy in patients with advanced non-small-cell lung cancer without epidermal growth factor receptor mutations. Jpn J. Clin. Oncol. 41, 959-963 (2011).

34. Coudert, B. et al. Survival benefit with erlotinib maintenance therapy in patients with advanced non-small-cell lung cancer (NSCLC) according to response to first-line chemotherapy. Ann. Oncol. http://dx.doi.org/10.1093/annonc/mdr125.

35. Reguart, N., Cardona, A. F. \& Rosell, R. Role of erlotinib in first-line and maintenance treatment of advanced non-small-cell lung cancer. Cancer Manag. Res. 2, 143-156 (2010)

36. Pan, Z. K. et al. Epidermal growth factor receptor mutation in Chinese patients with non-small cell lung cancer [Chinese]. Ai Zheng 24, 919-923 (2005).

37. NCl. A snapshot of head and neck cancerincidence and mortality rate trends [online], http://www.cancer.gov/aboutnci/servingpeople/ snapshots/head-neck.pdf (2011).
38. Burgos-Tiburcio, A., Santos, E. S., Arango, B. A. \& Raez, L. E. Development of targeted therapy for squamous cell carcinomas of the head and neck. Expert Rev. Anticancer Ther. 11, 373-386 (2011).

39. Baselga, J. et al. Phase I studies of antiepidermal growth factor receptor chimeric antibody $\mathrm{C} 225$ alone and in combination with cisplatin. J. Clin. Oncol. 18, 904-914 (2000).

40. Rubin, M. S. et al. Monoclonal antibody (MOAB) IMC-C225, an anti-epidermal growth factor receptor (EGFR), for patients (pts) with EGRFpositive tumors refractory to or in relapse from previous therapeutic regimens [abstract]. Proc. Am. Soc. Clin. Oncol. 19, a1860 (2000).

41. Mendelsohn, J. et al. A phase I study of chimerized anti-epidermal growth factor receptor (EGFR) monoclonal antibody, C225, in combination with cisplatin (CDDP) in patients (pts) with recurrent head and neck squamous cell carcinoma (SCC) [abstract]. Proc. Am. Soc. Clin. Oncol. 18, a1502 (1999).

42. Vermorken, J. B. et al. Platinum-based chemotherapy plus cetuximab in head and neck cancer. N. Engl. J. Med. 359, 1116-1127 (2008)

43. Iqbal, S. \& Lenz, H. J. Integration of novel agents in the treatment of colorectal cancer. Cancer Chemother. Pharmacol. 54 (Suppl. 1), S32-S39 (2004).

44. Hurwitz, H. et al. Bevacizumab plus irinotecan, fluorouracil, and leucovorin for metastatic colorectal cancer. N. Engl. J. Med. 350, 2335-2342 (2004).

45. Gambacorti-Passerini, C., Messa, C. \& Pogliani, E. M. Crizotinib in anaplastic large-cell lymphoma. N. Engl. J. Med. 364, 775-776 (2011).

46. Chabner, B. A. Early accelerated approval for highly targeted cancer drugs. N. Engl. J. Med. 364, 1087-1089 (2011)

47. Kwak, E. L. et al. Anaplastic lymphoma kinase inhibition in non-small-cell lung cancer. N. Engl. J. Med. 363, 1693-1703 (2010)

48. NCl. Cancer Trends Progress Report-2009/2010 Update [online], http:// progressreport.cancer.gov (2010).

49. Traynor, K. Ipilimumab approved for metastatic melanoma. Am. J. Health Syst. Pharm. 68, 768 (2011)

50. Hodi, F. S. et al. Improved survival with ipilimumab in patients with metastatic melanoma. N. Engl. J. Med. 363, 711-723 (2010).

51. Kaplan, F. M., Shao, Y., Mayberry, M. M. \& Aplin, A. E. Hyperactivation of MEK-ERK1/2 signaling and resistance to apoptosis induced by the oncogenic B-RAF inhibitor, PLX4720, in mutant N-RAS melanoma cells. Oncogene 30, 366-371 (2011)

52. Mehta, P. P. et al. A novel class of specific Hsp90 small molecule inhibitors demonstrate in vitro and in vivo anti-tumor activity in human melanoma cells. Cancer Lett. 300, 30-39 (2011).

53. Chapman, P. B. et al. Improved survival with vemurafenib in melanoma with BRAF V600E mutation. N. Engl. J. Med. 364, 2507-2516 (2011).

54. Flaherty, K. T. et al. Inhibition of mutated, activated BRAF in metastatic melanoma. N. Engl. J. Med. 363, 809-819 (2010).

55. Flaherty, K. T., Yasothan, U. \& Kirkpatrick, P. Vemurafenib. Nat. Rev. Drug Discov. 10, 811-812 (2011).

56. Kaelin Jr, W. G. The concept of synthetic lethality in the context of anticancer therapy. Nat. Rev. Cancer 5, 689-698 (2005).

57. Tutt, A. et al. Oral poly(ADP-ribose) polymerase inhibitor olaparib in patients with BRCA1 or BRCA2 mutations and advanced breast cancer: 
a proof-of-concept trial. Lancet 376, 235-244 (2010).

58. Audeh, M. W. et al. Oral poly(ADP-ribose) polymerase inhibitor olaparib in patients with BRCA1 or BRCA2 mutations and recurrent ovarian cancer: a proof-of-concept trial. Lancet 376, 245-251 (2010).

59. Fogelman, D. R. et al. Evidence for the efficacy of iniparib, a PARP-1 inhibitor, in BRCA2-associated pancreatic cancer. Anticancer Res. 31, 1417-1420 (2011)

60. Baselga, J. Targeting the phosphoinositide-3 (PI3) kinase pathway in breast cancer. Oncologist 16 (Suppl. 1), 12-19 (2011).

61. Sacco, A., Roccaro, A. \& Ghobrial, I. M. Role of dual PI3/Akt and mTOR inhibition in Waldenstrom's Macroglobulinemia. Oncotarget 1, 578-582 (2010).

62. Elfiky, A. A. et al. Characterization and targeting of phosphatidylinositol-3 kinase (PI3K) and mammalian target of rapamycin (mTOR) in renal cell cancer. J. Transl. Med. 9, 133 (2011).

63. Masuda, M., Shimomura, M., Kobayashi, K., Kojima, S. \& Nakatsura, T. Growth inhibition by NVP-BEZ235, a dual PI3K/mTOR inhibitor, in hepatocellular carcinoma cell lines. Oncol. Rep. 26, 1273-1279 (2011).

64. Gore, M. E. \& Larkin, J. M. Challenges and opportunities for converting renal cell carcinoma into a chronic disease with targeted therapies. Br. J. Cancer 104, 399-406 (2011).

65. Battelli, C. \& Cho, D. C. mTOR inhibitors in renal cell carcinoma. Therapy 8, 359-367 (2011).

66. Argyriou, P., Economopoulou, P. \& Papageorgiou, $\mathrm{S}$. The role of mTOR inhibitors for the treatment of B-cell lymphomas. Adv. Hematol. 2012, 435342 (2012).

67. Figueroa, J. A., De Raad, S., Speights, V. O. \& Rinehart, J. J. Gene expression of insulin-like growth factors and receptors in neoplastic prostate tissues: correlation with clinicopathological parameters. Cancer Invest. 19, 28-34 (2001).

68. Yap, T. A., Olmos, D., Molife, L. R. \& de Bono, J. S. Targeting the insulin-like growth factor signaling pathway: figitumumab and other novel anticancer strategies. Expert Opin. Investig. Drugs 20, 1293-1304 (2011).

69. Subbiah, V., Angelo, L. S. \& Kurzrock, R. Insulinlike growth factor 1 receptor (IGF-1R) inhibitor: another arrow in the quiver-will it hit the moving target? Expert Opin. Investig. Drugs 20, 1471-1477 (2011).

70. Jassem, J. et al. Randomized, open label, phase III trial of figitumumab in combination with paclitaxel and carboplatin versus paclitaxel and carboplatin in patients with non-small cell lung cancer (NSCLC) [abstract]. J. Clin. Oncol. 28 (Suppl. 15), a7500 (2010).

71. Beltran, P. J. et al. Efficacy of ganitumab (AMG 479), alone and in combination with rapamycin, in Ewing's and osteogenic sarcoma models. J. Pharmacol. Exp. Ther. 337, 644-654 (2011).

72. US National Library of Medicine. ClinicalTrials.gov [online], http://clinicaltrials.gov/ct2/show/ NCT01231347 (2011).

73. Keefe, D. M. \& Bateman, E. H. Gastrointestinal Toxicity of targeted Anti-Cancer Therapy. Treatment Strategies - Oncology [online], http:// viewer.zmags.com/ publication/8da7a9fc\#/8da7a9fc/ (2010).

74. Looyenga, B. D., Cherni, I., Mackeigan, J. P. \& Weiss, G. J. Tailoring tyrosine kinase inhibitors to fit the lung cancer genome. Transl. Oncol. 4, 59-70 (2011).

75. Antonescu, C. R. The GIST paradigm: lessons for other kinase-driven cancers. J. Pathol. 223, 251-261 (2011).
76. Bagnyukova, T. V. et al. Chemotherapy and signaling: How can targeted therapies supercharge cytotoxic agents? Cancer Biol. Ther. 10, 839-853 (2010).

77. Kunz, M. Genomic signatures for individualized treatment of malignant tumors. Curr. Drug Discov. Technol. 5, 9-14 (2008).

78. Logan, R. M. Advances in understanding of toxicities of treatment for head and neck cancer. Oral Oncol. 45, 844-848 (2009).

79. Sonis, S. T. et al. Perspectives on cancer therapyinduced mucosal injury: pathogenesis, measurement, epidemiology, and consequences for patients. Cancer 100, 1995-2025 (2004).

80. Elez, E., Macarulla, T. \& Tabernero, J. Handling side-effects of targeted therapies: safety of targeted therapies in solid tumours. Ann. Oncol. 19 (Suppl. 7), vii146-vii152 (2008).

81. Schmidinger, M. \& Bellmunt, J. Plethora of agents, plethora of targets, plethora of side effects in metastatic renal cell carcinoma. Cancer Treat. Rev. 36, 416-424 (2010).

82. Widakowich, C., de Castro Jr, G., de Azambuja, E., Dinh, P. \& Awada, A. Review: side effects of approved molecular targeted therapies in solid cancers. Oncologist 12, 1443-1455 (2007).

83. Ouwerkerk, J. \& Boers-Doets, C. Best practices in the management of toxicities related to antiEGFR agents for metastatic colorectal cancer. Eur. J. Oncol. Nurs. 14, 337-349 (2010).

84. Bamias, A. et al. The use of 24-h ambulatory blood pressure monitoring (ABPM) during the first cycle of sunitinib improves the diagnostic accuracy and management of hypertension in patients with advanced renal cancer. Eur. J. Cancer 47, 1660-1668 (2011).

85. Lacouture, M. E. et al. A proposed EGFR inhibitor dermatologic adverse event-specific grading scale from the MASCC skin toxicity study group. Support. Care Cancer 18, 509-522 (2010).

86. Pomerantz, R. G., Mirvish, E. D. \& Geskin, L. J. Cutaneous reactions to epidermal growth factor receptor inhibitors. J. Drugs Dermatol. 9, 1229-1234 (2010).

87. Lacouture, M. E. et al. Analysis of dermatologic events in patients with cancer treated with lapatinib. Breast Cancer Res. Treat. 114, 485-493 (2009).

88. Gerber, D. E. Targeted therapies: a new generation of cancer treatments. Am. Fam. Physician 77, 311-319 (2008)

89. Bhargava, P. VEGF kinase inhibitors: how do they cause hypertension? Am. J. Physiol. Regul. Integr. Comp. Physiol. 297, R1-R5 (2009).

90. Izzedine, H. et al. Management of hypertension in angiogenesis inhibitor-treated patients. Ann. Oncol. 20, 807-815 (2009).

91. Verheul, H. M. \& Pinedo, H. M. Possible molecular mechanisms involved in the toxicity of angiogenesis inhibition. Nat. Rev. Cancer 7, 475-485 (2007).

92. Gressett, S. M. \& Shah, S. R. Intricacies of bevacizumab-induced toxicities and their management. Ann. Pharmacother. 43, 490-501 (2009).

93. Saif, M. W. \& Mehra, R. Incidence and management of bevacizumab-related toxicities in colorectal cancer. Expert Opin. Drug Saf. 5, 553-566 (2006).

94. Walraven, M. et al. Antiangiogenic tyrosine kinase inhibition related gastrointestinal perforations: a case report and literature review. Angiogenesis 14, 135-141 (2011).

95. Muraoka, T. et al. lleal perforation induced by acute radiation injury under gefitinib treatment. Int. J. Clin. Oncol. http://dx.doi.org/10.1007/ s10147-011-0249-8.
96. Bose, D. et al. Vascular endothelial growth factor targeted therapy in the perioperative setting: implications for patient care. Lancet Oncol. 11, 373-382 (2010).

97. Gruenberger, B. et al. Bevacizumab, capecitabine, and oxaliplatin as neoadjuvant therapy for patients with potentially curable metastatic colorectal cancer. J. Clin. Oncol. 26, 1830-1835 (2008).

98. Eschenhagen, T. et al. Cardiovascular side effects of cancer therapies: a position statement from the Heart Failure Association of the European Society of Cardiology. Eur. J. Heart Fail. 13, 1-10 (2011).

99. Ewer, M. S. \& Ewer, S. M. Cardiotoxicity of anticancer treatments: what the cardiologist needs to know. Nat. Rev. Cardiol. 7, 564-575 (2010).

100. Kerkela, R. et al. Sunitinib-induced cardiotoxicity is mediated by off-target inhibition of AMPactivated protein kinase. Clin. Transl. Sci. 2, 15-25 (2009).

101. Bovelli, D., Plataniotis, G. \& Roila, F. Cardiotoxicity of chemotherapeutic agents and radiotherapy-related heart disease: ESMO Clinical Practice Guidelines. Ann. Oncol. 21 (Suppl. 5), v277-v282 (2010).

102. Harandi, A., Zaidi, A. S., Stocker, A. M. \& Laber, D. A. Clinical efficacy and toxicity of antiEGFR therapy in common cancers. J. Oncol. 2009, 567486 (2009).

103. Crown, J. P. et al. Pooled analysis of diarrhea events in patients with cancer treated with lapatinib. Breast Cancer Res. Treat. 112, 317-325 (2008).

104. Keefe, D. M. \& Gibson, R. J. Mucosal injury from targeted anti-cancer therapy. Support. Care Cancer 15, 483-490 (2007).

105. Bateman, E. et al. Further characterisation of epidermal growth factor receptor (EGFR) tyrosine kinase inhibitor-induced diarrhoea. Support. Care Cancer 19, S250 (2011).

106. Bowen, J. M. et al. Characterisation of EGF receptor tyrosine kinase inhibitor-induced diarrhoea. Support. Care Cancer 18, S77-S220 (2010).

107. Jean, G. W. \& Shah, S. R. Epidermal growth factor receptor monoclonal antibodies for the treatment of metastatic colorectal cancer. Pharmacotherapy 28, 742-754 (2008).

108. Hartmann, J. T., Haap, M., Kopp, H. G. \& Lipp, H. P. Tyrosine kinase inhibitors-a review on pharmacology, metabolism and side effects. Curr. Drug Metab. 10, 470-481 (2009).

109. Al-Dasooqi, N., Gibson, R., Bowen, J. \& Keefe, D. HER2 targeted therapies for cancer and the gastrointestinal tract. Curr. Drug Targets 10, 537-542 (2009).

110. Korpanty, G., Sullivan, L. A., Smyth, E., Carney, D. N. \& Brekken, R. A. Molecular and clinical aspects of targeting the VEGF pathway in tumors. J. Oncol. 2010, 652320 (2010).

111. van Erp, N. P., Gelderblom, H. \& Guchelaar, H. J. Clinical pharmacokinetics of tyrosine kinase inhibitors. Cancer Treat. Rev. 35, 692-706 (2009).

112. Pearson, S. A., Chin, M., Faedo, M. \& Ward, R. Rationale for treatment durations of targeted cancer agents. Lancet Oncol. 11, 1113-1115 (2010).

113. Duffy, M. J., O’Donovan, N. \& Crown, J. Use of molecular markers for predicting therapy response in cancer patients. Cancer Treat. Rev. 37, 151-159 (2011).

114. Meropol, N. J. et al. American Society of Clinical Oncology guidance statement: the cost of cancer care. J. Clin. Oncol. 27, 3868-3874 (2009). 
115. Abernethy, A. P. et al. Electronic patient-reported data capture as a foundation of rapid learning cancer care. Med. Care 48, S32-S38 (2010).

116. Eng, C. Toxic effects and their management: daily clinical challenges in the treatment of colorectal cancer. Nat. Rev. Clin. Oncol. 6, 207-218 (2009).

117. Amir, Z. \& Brocky, J. Cancer survivorship and employment: epidemiology. Occup. Med. (Lond.) 59, 373-377 (2009).

118. Feuerstein, M. et al. Work in cancer survivors: a model for practice and research. J. Cancer Surviv. 4, 415-437 (2010).

119. Grunfeld, E. A., Low, E. \& Cooper, A. F. Cancer survivors' and employers' perceptions of working following cancer treatment. Occup. Med (Lond.) 60, 611-617 (2010).

120. Grosse, S. D. Assessing cost-effectiveness in healthcare: history of the $\$ 50,000$ per QALY threshold. Expert Rev. Pharmacoecon. Outcomes Res. 8, 165-178 (2008).

121. Benedict, A. et al. Economic evaluation of new targeted therapies for the first-line treatment of patients with metastatic renal cell carcinoma. BJU Int. 108, 665-972 (2011).

122. Yardley, D. A. et al. Hormonal therapy plus bevacizumab in postmenopausal patients who have hormone receptor-positive metastatic breast cancer: a phase II Trial of the Sarah Cannon Oncology Research Consortium. Clin. Breast Cancer 11, 146-152 (2011).

123. Beijnen, J. H. \& Schellens, J. H. Personalized medicine in oncology: a personal view with myths and facts. Curr. Clin. Pharmacol. 5, 141-147 (2010).

124. Jonker, D. J. et al. Cetuximab for the treatment of colorectal cancer. N. Engl. J. Med. 357, 2040-2048 (2007).

125. Ulrich, J., Hartmann, J. T., Dorr, W. \& Ugurel, S. Skin toxicity of anti-cancer therapy. J. Dtsch. Dermatol. Ges. 6, 959-977 (2008).

126. Scartozzi, M. et al. Toward molecularly selected chemotherapy for advanced gastric cancer: state of the art and future perspectives. Cancer Treat. Rev. 35, 451-462 (2009).

127. Mir, O., Ropert, S., Alexandre, J. \& Goldwasser, F. Hypertension as a surrogate marker for the activity of anti-VEGF agents. Ann. Oncol. 20, 967-970 (2009).

128. Wolter, P. et al. The clinical implications of sunitinib-induced hypothyroidism: a prospective evaluation. Br. J. Cancer 99, 448-454 (2008).

129. Golshayan, A. R. et al. Metastatic sarcomatoid renal cell carcinoma treated with vascular endothelial growth factor-targeted therapy. J. Clin. Oncol. 27, 235-241 (2009).

130. Cho, W. C. OncomiRs: the discovery and progress of microRNAs in cancers. Mol. Cancer 6, 60 (2007)

131. Nicolas, F. E., Lopez-Gomollon, S., Lopez-Martinez, A. F. \& Dalmay, T. Silencing human cancer: identification and uses of
microRNAs. Recent Pat. Anticancer Drug Discov. 6, 94-105 (2011)

132. Schilsky, R. L. Personalized medicine in oncology: the future is now. Nat. Rev. Drug Discov. 9, 363-366 (2010).

133. Penel, N. et al. Predictors for establishing recommended phase 2 doses: analysis of 320 dose-seeking oncology phase 1 trials. Invest. New Drugs http://dx.doi.org/10.1007/ s10637-010-9574-4.

134. Takimoto, C. H. Maximum tolerated dose: clinical endpoint for a bygone era? Target Oncol. 4, 143-147 (2009).

135. Sleijfer, S. \& Wiemer, E. Dose selection in phase I studies: why we should always go for the top. J. Clin. Oncol. 26, 1576-1578 (2008).

136. Fernandez, A. \& Sessel, S. Selective antagonism of anticancer drugs for side-effect removal. Trends Pharmacol. Sci. 30, 403-410 (2009).

137. Maurea, N. et al. Women survive breast cancer but fall victim to heart failure: the shadows and lights of targeted therapy. J. Cardiovasc. Med. (Hagerstown) 11, 861-868 (2010).

138. Abernethy, A. P. et al. Validation of the Patient Care Monitor (Version 2.0): A review of system assessment instrument for cancer patients. J. Pain Symptom Manage. 40, 545-558 (2010).

139. NCl. Targeted Cancer Therapies - Fact Sheet [online], http://www.cancer.gov/cancertopics/ factsheet/Therapy/targeted (2011).

140. Wei, G., Rafiyath, S. \& Liu, D. First-line treatment for chronic myeloid leukemia: dasatinib, nilotinib, or imatinib. J. Hematol. Oncol. 3, 47 (2010).

141. Romero-Ventosa, E. Y. et al. Efficacy and toxicity of erlotinib in non-small cell lung cancer treatment. Farm. Hosp. http:// dx.doi.org/10.1016/j.farma.2010.12.005.

142. Mizota, A. et al. Retrospective analysis of cetuximab monotherapy for patients with irinotecan-intolerant metastatic colorectal cancer. Int. J. Clin. Oncol. 16, 416-420 (2011).

143. Ricciardi, S., Tomao, S. \& de Marinis, F. Toxicity of targeted therapy in non-small-cell lung cancer management. Clin. Lung Cancer 10, 28-35 (2009).

144. Pinto, C. et al. Phase II study of panitumumab, oxaliplatin, 5-fluorouracil, and concurrent radiotherapy as preoperative treatment in highrisk locally advanced rectal cancer patients (StarPan/STAR-02 Study). Ann. Oncol. 22, 2424-2430 (2011)

145. Wong, H. L. \& de Boer, R. H. Vandetanib for the treatment of non-small-cell lung cancer. Expert Opin. Pharmacother. 12, 2271-2278 (2011).

146. Ansell, S. M. et al. Temsirolimus and rituximab in patients with relapsed or refractory mantle cell lymphoma: a phase 2 study. Lancet Oncol. 12, 361-368 (2011).

147. Elter, T., Hallek, M. \& Montillo, M. Alemtuzumab: what is the secret to safe therapy? Clin. Adv. Hematol. Oncol. 9, 364-373 (2011).
148. Coiffier, B. et al. Safety and efficacy of ofatumumab, a fully human monoclonal anti-CD20 antibody, in patients with relapsed or refractory B-cell chronic lymphocytic leukemia: a phase 1-2 study. Blood 111, 1094-1100 (2008).

149. Di Giacomo, A. M., Biagioli, M. \& Maio, M. The emerging toxicity profiles of anti-CTLA-4 antibodies across clinical indications. Semin. Oncol. 37, 499-507 (2010).

150. Tarhini, A., Lo, E. \& Minor, D. R. Releasing the brake on the immune system: ipilimumab in melanoma and other tumors. Cancer Biother. Radiopharm. 25, 601-613 (2010).

151. Hall, P. S. et al. Updated cost-effectiveness analysis of trastuzumab for early breast cancer: A UK perspective considering duration of benefit, long-term toxicity and pattern of recurrence. Pharmacoeconomics 29, 415-432 (2011).

152. Purmonen, T. T., Pankalainen, E., Turunen, J. H., Asseburg, C. \& Martikainen, J. A. Short-course adjuvant trastuzumab therapy in early stage breast cancer in Finland: cost-effectiveness and value of information analysis based on the 5-year follow-up results of the FinHer Trial. Acta Oncol. 50, 344-352 (2011).

153. Tappenden, P., Jones, R., Paisley, S. \& Carroll, C. Systematic review and economic evaluation of bevacizumab and cetuximab for the treatment of metastatic colorectal cancer. Health Technol. Assess. 11, 1-128 iii-iv (2007).

154. Giuliani, G., Grossi, F., de Marinis, F. \& Walzer, S. Cost-effectiveness analysis of bevacizumab versus pemetrexed for advanced non-squamous NSCLC in Italy. Lung Cancer 69 (Suppl. 1), S11-S17 (2010).

155. Paz-Ares, L., del Muro, J. G., Grande, E. \& Diaz, S. A cost-effectiveness analysis of sunitinib in patients with metastatic renal cell carcinoma intolerant to or experiencing disease progression on immunotherapy: perspective of the Spanish National Health System. J. Clin. Pharm. Ther. 35, 429-438 (2010).

156. Ray, J. A., Carr, E., Lewis, G. \& Marcus, R. An evaluation of the cost-effectiveness of rituximab in combination with chemotherapy for the first-line treatment of follicular non-Hodgkin's lymphoma in the UK. Value Health 13, 346-357 (2010).

157. Joensuu, H., Trent, J. C. \& Reichardt, P. Practical management of tyrosine kinase inhibitorassociated side effects in GIST. Cancer Treat. Rev. 37, 75-88 (2011).

158. Keefe, D. et al. Noncardiac vascular toxicities of vascular endothelial growth factor inhibitors in advanced cancer: a review. Oncologist 16, 432-444 (2011)

Author contributions

Both authors researched data for the article, wrote the article, discussed the content of the manuscript and edited and reviewed the text before submission. 